\title{
LETHAL ENCEPHALITOZOONOSIS IN CYCLOPHOSPHAMIDE-TREATED RABBITS
}

\author{
M. HoRVÁTH ${ }^{1}$, L. LENG $^{2}$, M. ŠTEFKOVIČ ${ }^{3}$, Viera RÉVAJOVÁ ${ }^{1}$ and Monika HALANOVÁ ${ }^{3}$ \\ ${ }^{1}$ Department of Pathological Anatomy and ${ }^{3}$ Department of Biology, Genetics and Animal \\ Husbandry, University of Veterinary Medicine, Komenského 73, 04181 Košice, Slovak \\ Republic; ${ }^{2}$ Institute of Animal Physiology, Slovak Academy of Sciences, Košice, Slovak \\ Republic
}

(Received February 20, 1998; accepted June 11, 1998)

Encephalitozoonosis is an opportunistic infection in animals and humans. Its clinical form is observed in immunosuppressed hosts. We studied the occurrence of the manifest form of rabbit microsporidiosis under cyclophosphamide immunomodulation in 40 New Zealand rabbits. The experimental animals were intraperitoneally infected with $5 \times 10^{7}$ Encephalitozoon cuniculi spores. Two weeks after infection the animals were treated intraperitoneally with cyclophosphamide, first with $50 \mathrm{mg} / \mathrm{kg}$ and then with $15 \mathrm{mg} / \mathrm{kg}$ weekly during the 12-week experimental period. Positive controls were either E. cuniculi-infected or cyclophosphamide-immunosuppressed animals. The negative control rabbits remained untreated. Both clinical signs of encephalitozoonosis and depression of peripheral blood cell count developed between weeks 4 and 6 in the experimental animals which died during week 6 of the experiment. No clinical signs compatible with encephalitozoonosis were observed in any of the controls. The results suggest that immunosuppression induced by cyclophosphamide can give rise to a lethal form of encephalitozoonosis.

Key words: Encephalitozoon cuniculi, clinical signs, immunosuppression, peripheral leukocyte, rabbits

Encephalitozoonosis caused by Encephalitozoon cuniculi is a chronic, usually latent protozoonosis of rodents, carnivores, birds and primates. E. cuniculi is an obligate intracellular parasite of the phylum Microspora (Pakes and Gerrity, 1994). Clinical encephalitozoonosis is accompanied by neurological signs, e.g. paralysis and convulsion (Bálent et al., 1995). In rabbits, Levkut et al. (1997) have assumed that bovine leukaemia virus acts as a factor predisposing rabbits to clinically apparent encephalitozoonosis. Lethal disease is typical of Tand B-lymphocyte immunodeficient (SCID) mice (Koudela et al., 1993). Microsporidia have been referred to as opportunistic pathogens in humans with AIDS (Weber et al., 1994). Recently, Mathis et al. (1997) has found a rabbit E. cuniculi isolate, classified by Didier et al. (1995) as strain I, in the urine of people, confirming the zoonotic character of the disease. 
Cyclophosphamide (CY) is an immunosuppressive, cytotoxic drug, a chemical derivative of mechloretamine (Boumpas et al., 1993). CY has been used in the therapy of neoplastic (De Forni and Armand, 1994) and autoimmune diseases (Bradley et al., 1989). The immunosuppressive and cytotoxic effects of CY are based upon an alkylating reaction with cell DNA (Steinberg, 1993). Haematological toxicity is its best-known action. CY suppresses all cell lines within the bone marrow. Maximal depression of circulating granulocytes and lymphocytes occurs at 7-14 days after treatment with a single dose of CY (McCune et al., 1988). Similarly, a single dose of CY led to a $60 \%$ decrease of both T and B lymphocyte numbers in the spleen (Austin et al., 1997).

The aim of this work was to study the relationship between the quantitative changes of peripheral leukocyte count and the occurrence of clinically manifest encephalitozoonosis in rabbits immunosuppressed with cyclophosphamide.

\section{Materials and methods}

\section{Parasite}

A rabbit isolate of E. cuniculi (provided by a laboratory of O. Ditrich, Parasitology Institute, Czech Republic) was grown in E-6 cell (Vero green monkey kidney cell) for provision of spores. The cells were cultivated in modified RPMI 1640 medium supplemented with $5 \%$ fetal calf serum. The parasites used for inoculation were freshly collected from the culture supernatant after centrifugation at $400 \mathrm{~g}$ for $30 \mathrm{~min}$, washed by centrifugation in phosphate-buffered saline (PBS), counted on haemocytometer, and adjusted to the desired concentration.

\section{Animals and experimental procedure}

Forty New Zealand White rabbits of both sexes (4 months old; $2.5 \pm$ $0.5 \mathrm{~kg}$ in weight), free of E. cuniculi, coccidial and Pasteurella infection, were used in the experiment. Four groups of ten rabbits each were housed under conventional conditions with free access to water and feed. Animals of the first group, designated as $\mathrm{Ec}^{+} \mathrm{Cy}^{+}$, were infected by intraperitoneal (i.p.) injection of $5 \times 10^{7}$ E. cuniculi spores in $1 \mathrm{ml}$ PBS. In order to induce immunosuppression, this group was treated intraperitoneally with two dosages of $\mathrm{CY}$ once weekly during a period of 12 weeks. The first CY dosage of $50 \mathrm{mg} / \mathrm{kg}$ was applied on day 14 after E. cuniculi administration, and then $15 \mathrm{mg} / \mathrm{kg} \mathrm{CY}$ was given once a week for period of 12 weeks.

The groups designated as $\mathrm{Ec}^{+} \mathrm{Cy}^{-}$and $\mathrm{Ec}^{-} \mathrm{Cy}^{+}$served as positive controls and were treated as follows: group $\mathrm{Ec}^{+} \mathrm{Cy}^{-}$was infected i.p. with $5 \times 10^{7}$ E. cuniculi spores, while group $\mathrm{Ec}^{-} \mathrm{Cy}^{+}$was treated only with $\mathrm{CY}$. No treatment 
was done in $\mathrm{Ec}^{-} \mathrm{Cy}^{-}$which served as negative control. Rabbits of groups $\mathrm{Ec}^{+} \mathrm{Cy}^{+}$ and $\mathrm{Ec}^{+} \mathrm{Cy}^{-}$were kept individually and isolated from the other groups. The animals were killed in week 12 after the first application of CY. Body weight was measured weekly.

\section{Indirect immunofluorescence antibody test (IFAT)}

The IFAT method was used to determine specific anti-E. cuniculi antibodies. The method was performed according to Chalupský et al. (1973). Fresh suspension of E. cuniculi from tissue culture was placed on each well of a slide. The slides were air-dried for $24 \mathrm{~h}$, then fixed in absolute acetone for $15 \mathrm{~min}$ and airdried. Rabbit sera tested were serially diluted beginning at 1:4 and ending at 1:512. Each of the wells on the slide was covered with $10 \mu \mathrm{l}$ diluted serum, and slides were incubated for $30 \mathrm{~min}$ at $37{ }^{\circ} \mathrm{C}$ within a moist chamber. The slides were then washed twice in distilled water and PBS at 10-min intervals. Following air-drying, the wells were covered with $10 \mu 1$ of swine anti-rabbit immunoglobulin fluorescein isothiocyanate conjugate (SEVAC, Prague) of 1:160 dilution. After $30 \mathrm{~min}$ at $37^{\circ} \mathrm{C}$ the slides were washed and air-dried. Then they were counter-stained with Evans blue and coverslips mounted with buffered glycerine.

\section{Blood leukocyte count}

CY-induced immunosuppression was estimated by means of white blood cell count. The blood samples were collected two weeks after primary CY treatment and later biweekly from the marginal aural vein into Turk's solution. The cells were then counted in a haemocytometer. Differential cell counts were made on blood smears after May-Grünwald-Giemsa staining by counting 100 leukocytes per slide.

\section{Data evaluation}

Results are quoted as the mean \pm SEM. The data were statistically evaluated by the one-way analysis of variance (ANOVA) with post hoc Bonferroni multiple-comparison test. Differences between groups at the level of $p<0.05$ were considered significant.

\section{Results}

$\mathrm{Ec}^{+} \mathrm{Cy}^{+}$rabbits showed a significant decrease in body weight between weeks 8 and 12 in comparison to the $\mathrm{Ec}^{-} \mathrm{Cy}^{+}$or $\mathrm{Ec}^{+} \mathrm{Cy}^{-}$controls (Table 1). Three $\mathrm{Ec}^{+} \mathrm{Cy}^{+}$animals developed non-parasitic alopecia on the back, incontinent urination, ataxia, torticollis, convulsions, paresis and paralysis of the hind limbs in week 5. These rabbits died in week 6 . The above-mentioned alopecia was also observed in the $\mathrm{Ec}^{-} \mathrm{CY}^{+}$control. 
Table 1

Changes of body weight in E. cuniculi-infected rabbits during treatment with cyclophosphamide

\begin{tabular}{ccccc}
\hline \multirow{2}{*}{$\begin{array}{c}\text { Period after first } \\
\text { CY dosage (week) }\end{array}$} & \multicolumn{4}{c}{ Body weight $(\mathrm{kg})$} \\
\cline { 2 - 5 } & $\mathrm{Ec}^{+} \mathrm{Cy}^{+}$ & $\mathrm{Ec}^{+} \mathrm{Cy}^{-}$ & $\mathrm{Ec}^{-} \mathrm{Cy}^{+}$ & $\mathrm{Ec}^{-} \mathrm{Cy}^{-}$ \\
\hline 2 & $2.69 \pm 0.100$ & $2.92 \pm 0.122$ & $2.73 \pm 0.129$ & $2.75 \pm 0.085$ \\
4 & $2.46 \pm 0.099$ & $2.66 \pm 0.114$ & $2.59 \pm 0.123$ & $2.82 \pm 0.065$ \\
6 & $2.50 \pm 0.089$ & $2.67 \pm 0.084$ & $2.56 \pm 0.117$ & $2.87 \pm 0.085$ \\
8 & $2.48 \pm 0.082^{\mathrm{ab}}$ & $2.68 \pm 0.074$ & $2.84 \pm 0.097^{\mathrm{a}}$ & $2.92 \pm 0.057^{\mathrm{b}}$ \\
10 & $2.75 \pm 0.094^{\mathrm{a}}$ & $2.69 \pm 0.083^{\mathrm{b}}$ & $3.18 \pm 0.121^{\mathrm{ab}}$ & $3.06 \pm 0.059^{\mathrm{b}}$ \\
12 & $2.72 \pm 0.081^{\mathrm{a}}$ & $2.82 \pm 0.078^{\mathrm{b}}$ & $3.06 \pm 0.117^{\mathrm{a}}$ & $3.27 \pm 0.066^{\mathrm{ab}}$ \\
& & &
\end{tabular}

Same superscript means significantly different group * $(p<0.05)$ within the same week

Sera from both the $\mathrm{Ec}^{+} \mathrm{Cy}^{+}$rabbits and $\mathrm{Ec}^{+} \mathrm{Cy}^{-}$control reacted in the IFAT by titres higher than 1:64 two weeks after the experimental E. cuniculi-infection. Animals from other groups remained without specific anti-E. cuniculi antibodies in the serum until the end of experiment.

Haematological analysis of $\mathrm{Ec}^{+} \mathrm{Cy}^{+}$rabbits showed the following changes in the number of white blood cells (WBC). Progressive decrease in WBC occurred in weeks 4 and 6 . In the same period, WBC count of $\mathrm{Ec}^{+} \mathrm{Cy}^{+}$rabbits was significantly lower in comparison to each control group (Table 2). Eosinophilia was noticed in week 2 whereas severe eosinopenia was observed between weeks 4 and 6 (Table 3 ). Basophils decreased in two phases, in weeks 6 and 12 (Table 4). The number of peripheral lymphocytes sharply decreased up to week 6 (Fig. 1). Monocyte numbers declined in week 4 and then peaked in week 10 (Fig. 2). Heterophils decreased in two waves, the first in week 4, and the second in week 12 (Fig. 3). The results of haematological examinations of the control groups are summarised in the same tables and figures.

\section{Table 2}

White blood cell count in E. cuniculi-infected rabbits during treatment with cyclophosphamide

\begin{tabular}{ccccc}
\hline \multirow{2}{*}{$\begin{array}{c}\text { Period after first } \\
\text { CY dosage (week) }\end{array}$} & \multicolumn{4}{c}{ White blood cell count $\left(10^{9} / 1\right)$} \\
\cline { 2 - 5 } & $\mathrm{Ec}^{+} C y^{+}$ & $\mathrm{Ec}^{+} C y^{-}$ & $\mathrm{Ec}^{-} \mathrm{Cy}^{+}$ & $\mathrm{Ec}^{-} \mathrm{Cy}^{-}$ \\
\hline 2 & $8.10 \pm 0.365$ & $8.08 \pm 0.413$ & $7.90 \pm 0.244^{\mathrm{a}}$ & $9.46 \pm 0.429^{\mathrm{a}}$ \\
4 & $6.38 \pm 0.367^{\mathrm{a}}$ & $7.09 \pm 0.611^{\mathrm{b}}$ & $7.17 \pm 0.707^{\mathrm{c}}$ & $10.01 \pm 0.419^{\mathrm{abc}}$ \\
6 & $5.12 \pm 0.390^{\mathrm{a}}$ & $7.12 \pm 0.463^{\mathrm{ab}}$ & $7.76 \pm 0.436^{\mathrm{ac}}$ & $9.76 \pm 0.395^{\mathrm{abc}}$ \\
8 & $5.33 \pm 0.332^{\mathrm{a}}$ & $8.75 \pm 0.325^{\mathrm{ab}}$ & $7.10 \pm 0.259^{\mathrm{abc}}$ & $7.90 \pm 0.376^{\mathrm{ac}}$ \\
10 & $5.97 \pm 0.397^{\mathrm{a}}$ & $8.35 \pm 0.392^{\mathrm{ab}}$ & $5.32 \pm 0.528^{\mathrm{bc}}$ & $10.00 \pm 0.297^{\mathrm{ac}}$ \\
12 & $5.58 \pm 0.359^{\mathrm{a}}$ & $9.01 \pm 0.338^{\mathrm{ab}}$ & $6.22 \pm 0.424^{\mathrm{bc}}$ & $11.80 \pm 0.391^{\mathrm{ac}}$ \\
\hline
\end{tabular}

Same superscript means significantly different group $*(p<0.05)$ within the same week 
Table 3

Eosinophils in E. cuniculi-infected rabbits during treatment with cyclophosphamide

\begin{tabular}{ccccc}
\hline \multirow{2}{*}{$\begin{array}{c}\text { Period after first } \\
\text { CY dosage (week) }\end{array}$} & $\mathrm{Ec}^{+} \mathrm{Cy}^{+}$ & $\mathrm{Ec}^{+} \mathrm{Cy}^{-}$ & $\mathrm{Ec}^{-} \mathrm{Cy}^{+}$ & $\mathrm{Ec}^{-} \mathrm{Cy}^{-}$ \\
\cline { 2 - 5 } & $0.041 \pm 0.021$ & $0.030 \pm 0.037$ & $0.021 \pm 0.244$ & $0.160 \pm 0.037$ \\
2 & $0.010 \pm 0.020$ & $0.001 \pm 0.018$ & $0.001 \pm 0.027$ & $0.180 \pm 0.029$ \\
4 & $0.001 \pm 0.024$ & $0.010 \pm 0.027$ & $0.013 \pm 0.019$ & $0.290 \pm 0.037$ \\
6 & $0.020 \pm 0.022$ & $0.020 \pm 0.040$ & $0.023 \pm 0.240$ & $0.004 \pm 0.146$ \\
8 & $0.010 \pm 0.021$ & $0.026 \pm 0.028$ & $0.011 \pm 0.009$ & $0.210 \pm 0.042$ \\
10 & $0.110 \pm 0.018$ & $0.214 \pm 0.035$ & $0.022 \pm 0.016$ & $0.220 \pm 0.040$ \\
\hline
\end{tabular}

Same superscript means significantly different group $*(p<0.05)$ within the same week

Table 4

Basophils in E. cuniculi-infected rabbits during treatment with cyclophosphamide

\begin{tabular}{ccccc}
\hline \multirow{2}{*}{$\begin{array}{c}\text { Period after first } \\
\text { CY dosage (week) }\end{array}$} & \multicolumn{4}{c}{ Basophils $\left(10^{9} / 1\right)$} \\
\cline { 2 - 5 } & $\mathrm{Ec}^{+} \mathrm{Cy}^{+}$ & \multicolumn{4}{c}{$\mathrm{Ec}^{+} \mathrm{Cy}^{-}$} & $\mathrm{Ec}^{-} \mathrm{Cy}^{+}$ & $\mathrm{Ec}^{-} \mathrm{Cy}^{-}$ \\
\hline 2 & $0.110 \pm 0.018$ & $0.110 \pm 0.010$ & $0.051 \pm 0.014$ & $0.116 \pm 0.034$ \\
4 & $0.012 \pm 0.010^{\mathrm{a}}$ & $0.114 \pm 0.001$ & $0.043 \pm 0.001$ & $0.128 \pm 0.038^{\mathrm{a}}$ \\
6 & $0.071 \pm 0.001^{\mathrm{a}}$ & $0.167 \pm 0.001^{\mathrm{b}}$ & $0.066 \pm 0.006^{\mathrm{c}}$ & $0.190 \pm 0.039^{\mathrm{abc}}$ \\
8 & $0.128 \pm 0.007$ & $0.144 \pm 0.090$ & $0.062 \pm 0.010$ & $0.049 \pm 0.015$ \\
10 & $0.098 \pm 0.009^{\mathrm{a}}$ & $0.139 \pm 0.010$ & $0.035 \pm 0.006^{\mathrm{a}}$ & $0.102 \pm 0.732$ \\
12 & $0.066 \pm 0.006$ & $0.234 \pm 0.008$ & $0.042 \pm 0.007$ & $0.155 \pm 0.031$ \\
\hline
\end{tabular}

Same superscript means significantly different group $*(p<0.05)$ within the same week

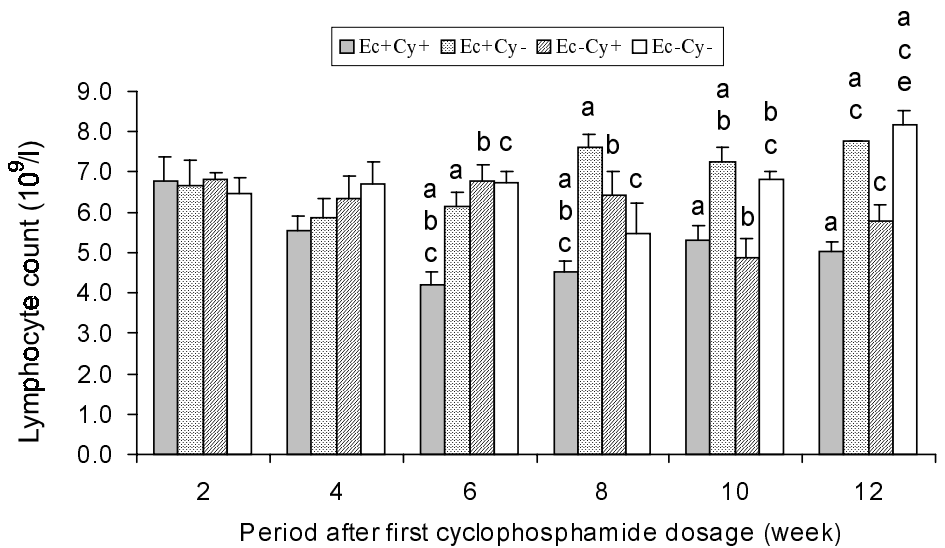

Fig. 1. Changes in the lymphocyte counts of E. cuniculi infected rabbits during cyclophosphamide treatment. Same superscript means significantly different group $*(p<0.05)$ within the same week 


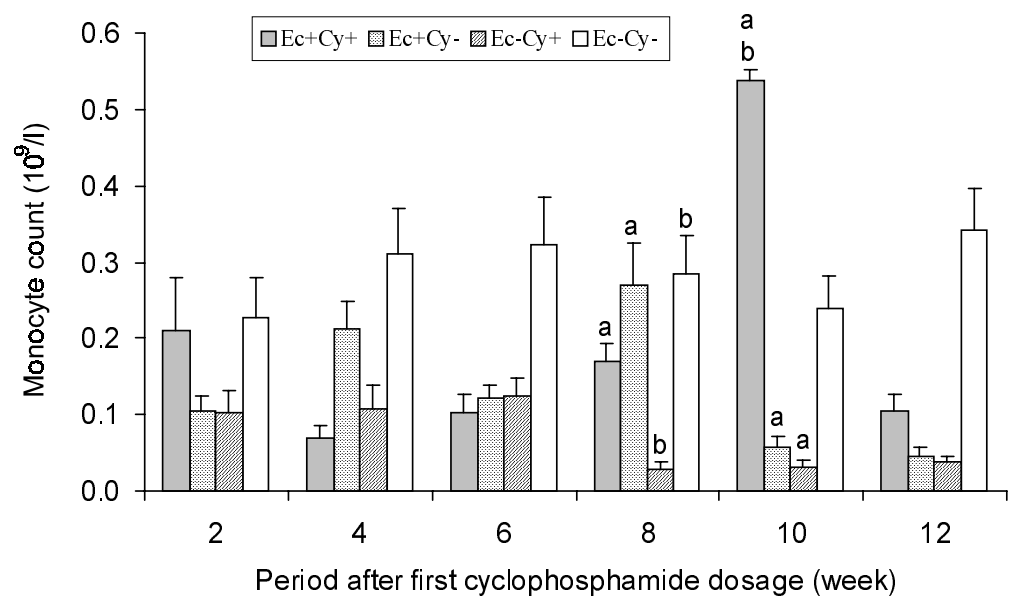

Fig. 2. Changes in the monocyte counts of E. cuniculi infected rabbits during cyclophosphamide treatment. Same superscript means significantly different group $*(p<0.05)$ within the same week

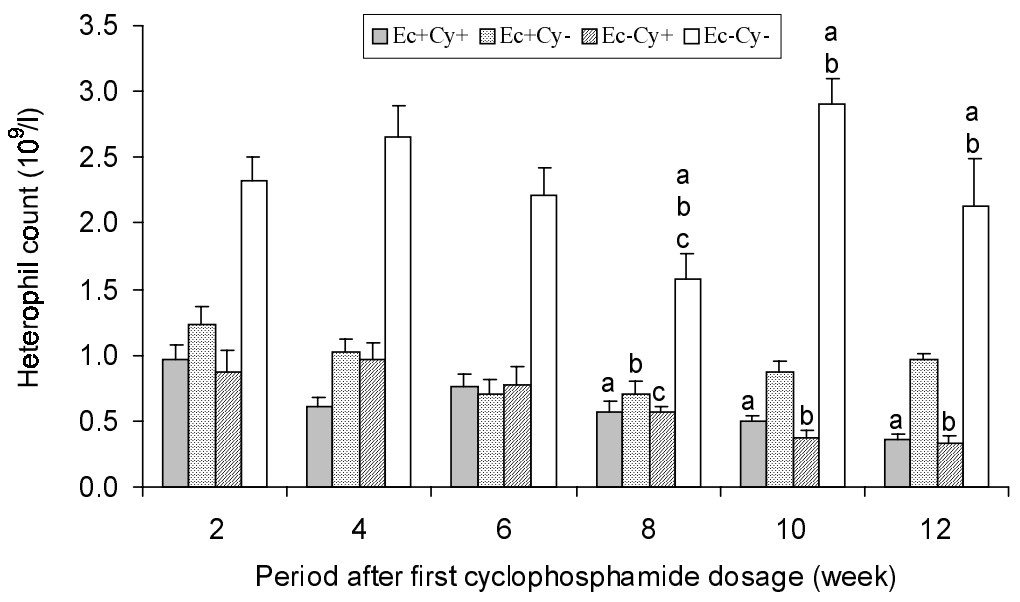

Fig. 3. Changes in the heterophil counts of E. cuniculi infected rabbits during cyclophosphamide treatment. Same superscript means significantly different group $*(p<0.05)$ within the same week

\section{Discussion}

Overt clinical signs of encephalitozoonosis in rabbits are variable, but infection is usually subclinical. Rabbits occasionally develop motor paralysis, convulsions and torticollis (Levkut et al., 1996). Currently, Pástorová et al. (1997) have suggested that the level of catecholamine is significantly lower in spontane- 
ous cases of rabbit encephalitozoonosis. On the other hand, carnivores infected with E. cuniculi were found to have retarded growth, total or partial blindness, bilateral thickening of the irises, and dilatation of retinal vessels (Botha et al., 1979). Moreover, ocular changes also include superficial and deep keratitis, retinitis and cataracts (Arnensen and Norstoga, 1977). Carnivores are known to die of encephalitis or uraemia due to chronic renal failure (Stewart et al., 1988).

We have found leukopenia and the decrease in white blood cell types. The lowest count of peripheral leukocytes was observed from week 4 to week 6 of the experiment in $\mathrm{Ec}^{+} \mathrm{Cy}^{+}$rabbits. It is generally accepted that $\mathrm{CY}$ has a complex immunomodulatory effect on diverse aspects of the immune response. It is metabolised by hepatic microsomal cytochrome P-450 enzymes to several metabolites such as 4-hydroxycyclophosphamide, phosphoramide mustard, acrolein, and others. These diverse metabolites are responsible for mediating the therapeutic and toxic effects (Fox and McCune, 1994). Target tissues of CY include the bone marrow as well as lymphoid cells and organs. In the spleen, a decrease in T and B lymphocyte counts was recorded (Ladics and Loveless, 1994). Previous studies have led to the conclusion that lymphopenic leukopenia is the hallmark of CY immunomodulatory action in peripheral blood (Binta et al., 1996).

Significant body weight loss was found in $\mathrm{Ec}^{+} \mathrm{Cy}^{+}$animals. Hair loss was observed in $\mathrm{Ec}^{+} \mathrm{Cy}^{+}$rabbits and $\mathrm{Ec}^{-} \mathrm{Cy}^{+}$controls from week 6. Neurological signs were found in the $\mathrm{Ec}^{+} \mathrm{Cy}^{+}$group while no control animals developed similar disorder. Loss of body weight, nonparasitic alopecia, neurological abnormalities, anorexia and vomiting are known side effects of CY (Levkut, 1981).

At week 5, three $\mathrm{Ec}^{+} \mathrm{Cy}^{+}$rabbits developed clinical signs of the disease such as incontinent urination, ataxia, tremor, paresis and paralysis of hind limbs. Animals with clinical signs died in week 6 of CY treatment. It has been shown that encephalitozoonosis remains latent as long as parasite multiplication and host immune response are balanced. An intact thymus is required for protective immunity, since euthymic BALB/c mice had chronic asymptomatic infections, while athymic nude mice of this strain developed acute and lethal infections (Gannon, 1980). In addition, previous studies demonstrated that pre-treatment of E. cuniculi with immune sera reduced spore viability (Schmidt and Shadduck, 1984).

Our results showed that a low dose of $\mathrm{CY}$ given repeatedly can reactivate latent encephalitozoonosis via immunosuppression. Rabbits under CY treatment appear to be a useful model for the study of immunopathological mechanisms involved in the interaction between $E$. cuniculi or other microsporidian pathogens and an immunodeficient host. Although the experiment demonstrated that latent encephalitozoonosis developed into lethal disease as immunodeficiency progressed, further studies are required to clarify whether a rabbit must be immunodeficient to become susceptible to manifest form of encephalitozoonosis. 


\section{Acknowledgement}

We thank Mr. John A. Allen for excellent language correction of the manuscript. This study was supported by the Scientific Grant Agency - grant no. 1/4223/97.

\section{References}

Arnensen, K. and Norstoga, K. (1977): Ocular encephalitozoonosis (nosematosis) in blue foxes: polyarteritis nodosa and cataract. Acta Ophthalmol. 55, 641-651.

Austin, H. A., Patel, A. D., Cadena, C. A., Boumpas, D. T. and Balow, J. E. (1997): Ongoing immunologic activity after short courses of pulse cyclophosphamide in the NZB/W murine model of systemic lupus erythematosus. J. Rheumatol. 24, 61-68.

Bálent, P., Kolodzieyski, L. and Hipíková, V. (1995): Encephalitozoonosis - an actual disease in rabbits also in Slovakia (in Slovak). Slov. Vet. J. 20, 81-83.

Binta, M. G., Mushi, E. Z. and Rurangirva, F. R. (1996): Effect of cyclophosphamide on the acquisition of resistance to infestation by Rhipicephalus appendiculatus in rabbits. Onderstepoort J. Vet. Res. 63, 7-10.

Botha, V. S., Van Dellen, A. F. and Stewart, C. G. (1979): Canine encephalitozoonosis in South Africa. J. South Afr. Vet. Assoc. 50, 135-144.

Boumpas, D. T., Chrousos, G. P., Wilder, R. L., Wilder, T. R., Cupps, T. R. and Balow, J. E. (1993): Glucocorticoid therapy for immune-mediated diseases: basic and clinical correlates. Ann. Inter. Med. 119, 1198-1208.

Bradley, J. D., Brandt, K. D. and Katz, B. P. (1989): Infectious complications of cyclophosphamide treatment for vasculitis. Arthritis Rheum. 32, 45-53.

Chalupský, J., Vávra, J. and Bedrník, P. (1973): Detection of antibodies to Encephalitozoon cuniculi in rabbits by the indirect immunofluorescent antibody test. Folia Parasit. 20, 281-284.

De Forni, M. and Armand, J. P. (1994): Cardiotoxicity of chemotherapy. Curr. Opinion Oncol. 6, $340-344$.

Didier, E. S., Vossbrinck, C. R., Baker, M. D., Rogers, L. B., Bertucci, D. C. and Shadduck, J. A. (1995): Identification and characterisation of three Encephalitozoon cuniculi strains. Parasitol. 111, 411-421.

Fox, D. A. and McCune, W. J. (1994): Immunosuppressive drug therapy of systemic lupus erythematosus. Rheum. Dis. Clin. North Am. 20, 265-299.

Gannon, J. (1980): The course of infection of Encephalitozoon cuniculi in immunodeficient and immunocompetent mice. Lab. Animals 14, 91-94.

Koudela, B., Vítovec, J., Ditrich, O. and Trávniček, J. (1993): The severe combined immunodeficient mouse as a model for Encephalitozoon cuniculi microsporidiosis. Folia Parasit. 40, 279-286.

Ladics, G. S. and Loveless, S. E. (1994): Cell surface marker analysis of splenic lymphocyte populations of the CD rat for use in immunotoxicological studies. Toxicol. Methods 4, 77-91.

Levkut, M. (1981): Effect of cyclophosphamide on avian sarcoma infected rats. In: M. Levkut (ed.) Pathomorphological Study of Avian Sarcomatosis (in Slovak). PhD Thesis, University of Veterinary Medicine, Košice, pp. 105-114.

Levkut, M., Lešník, F., Bálent, P., Zajac, V., Korim, P. and Sláviková, K. (1997): Bovine leukemia virus-induced clinical signs and morphological changes of encephalitozoonosis in rabbits. Folia Parasit. 44, 249-259. 
Levkut, M., Levkutová, M., Hipíková, V., Kolodzieyski, L., Bálent, P. and Bajová, V. (1996): Demonstration of antibodies to Encephalitozoon cuniculi in rabbits on some Slovak farms. Helminthologia 33, 25-26.

Mathis, A., Michel, M., Muller, C., Weber, R. and Deplazes, P. (1997): Two Encephalitozoon cuniculi strains of human origin are infectious to rabbits. Parasitol. 114, $29-35$.

McCune, W. J., Golbus, J., Zeldes, W., Bohlke, P., Dunne, R. and Fox, D. A. (1988): Clinical and immunologic effects of monthly administration of intravenous cyclophosphamide in severe systemic lupus erythematosus. N. Engl. J. Med. 318, 1423-1431.

Pakes, S. P. and Gerrity, L. W. (1994): Protozoal diseases. In: Manning, P. J., Ringler, D. H. and Newcomber, C. E. (eds) The Biology of the Laboratory Rabbit. Academic Press Inc., San Diego, p. 215.

Pástorová, B., Ryboš, M., Eliáš, V. and Várady, J. (1997): Levels of catecholamines in blood plasma of rabbits naturally infected with Encephalitozoon cuniculi. Helminthologia 34, 23-26.

Schmidt, E. C. and Shadduck, J. A. (1984): Mechanisms of resistance to the intracellular protozoan Encephalitozoon cuniculi in mice. J. Immunol. 133, 2712-2719.

Steinberg, A. D. (1993): Chlorambucil in the treatment of patients with immune mediated rheumatic diseases. Arthritis Rheum. 36, 325-328.

Stewart, C. G., Reyers, F. and Snyman, H. (1988): The relationship in dogs between primary renal disease and antibodies to Encephalitozoon cuniculi. J. South Afr. Vet. Assoc. 59, 19-21.

Weber, R., Bryan, R. T., Schwartz, D. A. and Owen, R. L. (1994): Human microsporidial infections. Clin. Microbiol. Rev. 7, 426-461. 